\title{
BMJ Open Experiences and explanations of mental ill health in a group of devout Christians from the ethnic majority population in secular Sweden: a qualitative study
}

\author{
Aina Lilja, ${ }^{1}$ Valerie DeMarinis, ${ }^{1,2,3}$ Arja Lehti, ${ }^{4}$ Annika Forssén ${ }^{1}$
}

To cite: Lilja A, DeMarinis V, Lehti $A$, et al. Experiences and explanations of mental ill health in a group of devout Christians from the ethnic majority population in secular Sweden: a qualitative study. BMJ Open 2016;6:e011647. doi:10.1136/bmjopen-2016011647

- Prepublication history for this paper is available online. To view these files please visit the journal online (http://dx.doi.org/10.1136/ bmjopen-2016-011647).

Received 23 February 2016 Revised 19 September 2016 Accepted 30 September 2016

CrossMark

For numbered affiliations see end of article.

\section{Correspondence to} Dr Annika Forssén; annika.forssen@nll.se

\section{ABSTRACT}

Objective: To explore existential meaning-making in an ethnic-majority subgroup with mental ill health and to increase knowledge about the importance of gaining access to such information in mental healthcare.

Design: Qualitative study using in-depth interviews and systematic text condensation analysis.

Participants: 17 devote Christians with an ethnicSwedish background, 12 women and 5 men, 30-73 years old, from different congregations across Sweden, having sought medical care for mental ill health of any kind.

Setting: The secular Swedish society.

Results: A living, although asymmetric, relationship with God often was seen as the most important relationship, giving hope and support when ill, but creating feelings of abandonment and fear if perceived as threatened. Symptoms were interpreted through an existential framework influenced by their view of God. A perceived judging God increased feelings of guilt, sinfulness and shame. A perceived merciful God soothed symptoms and promoted recovery. Existential consequences, such as being unable to pray or participate in congregational rituals, caused feelings of 'spiritual homelessness'. Participants gave biopsychosocial explanations of their mental ill health, consonant with and sometimes painfully conflicting with existential explanations, such as being attacked by demons. Three different patterns of interaction among biopsychosocial and existential dimensions in their explanatory systems of illness causation were identified: (a) comprehensive thinking and consensus; (b) division and parallel functions and (c) division and competitive functions.

Conclusions: Prevailing medical models for understanding mental ill health do not include the individual's existential experiences, which are important for identifying risk and protective factors as well as possible resources for recovery. The various expressions of existential meaning-making identified in this devout religious subgroup illustrate that existential information cannot be generalised, even within a small, seemingly homogenous group. The three identified patterns of interactions formed a typology that may be of use in clinical settings.

\section{Strengths and limitations of this study}

- This study on experiences of mental ill health is qualitative and contributes original empirical data on an understudied minority within an ethnic majority, that of devout Christians in a highly secular context.

- The participants represent a broad variation regarding symptomology, diagnosis, gender, age, class, sexual identity and denominational affiliation, while also reflecting the cultural dominance of Lutheranism in the Swedish society.

- The project was performed by a multidisciplinary team, with long clinical experience of treating mental ill health.

- An interviewer well aquatinted with the participants' religious belief system proved important, increasing trust for participants and providing a rich material, but also increasing the risk of shared blindness to certain aspects.

- For ethical reasons, we chose to include only participants relatively stable in their illness experiences, implying that some experiences may have been forgotten or too difficult to raise in the interviews, a fact that might have had an impact on the results.

\section{INTRODUCTION}

Mental ill health is designated as one of the largest future health problems in the Western world. $^{1}{ }^{2}$ In the summary report of the European-wide ROAMER study, a roadmap for public mental health research, ${ }^{3}$ the first priority area focuses on positive mental health, protective factors and well-being. The second area underscores the need for an interdisciplinary perspective for understanding mental health complexities. The third area calls for strengthening the understanding of cultural factors (ie, ethnicity, religion and value systems and nationality) relevant for public mental health. Attention to this third area in dialogue with the first and second provides the overall framework here. 
Mental ill health is classified as descriptive symptom diagnoses according to either of the two operative systems ICD or DSM, implying that understanding symptom expression needs to be sensitive to differences in culture, social groups and systems of meaning. Attention to existential information as part of cultural information in the diagnostic process has been emphasised in person-centred mental healthcare by the $\mathrm{WHO}^{4}$ and in the new DSM- $5 .{ }^{5}$

In Western countries, an attempt to explain the complexity of mental ill-health causation is the biopsychosocial model. ${ }^{6}$ The model has become established not least in mental health contexts, though the definitions and operationalisations of the concepts vary in different cultural contexts. It has also been criticised as insufficient, since it does not account for the individual's underlying meaning system which affects development and interpretation of symptoms. ${ }^{7} 8$ Though meant to offer a more complete and integrated understanding, its operationalisation into separate components might lead to the opposite, losing sight of the lived body marked by all experiences. ${ }^{9}$ Inclusion of an existential component, as central for the integrating process, has begun to gain attention in mental health contexts. ${ }^{7}$

Healthcare researchers in Scandinavia suggest integrating the biopsychosocial model with existential meaning-making, understood in cultural context. ${ }^{10}{ }^{11}$ Existential meaning-making here includes all types and expressions of how meaning is made, such as traditional religious expressions, other worldview expressions including atheism or more privately constructed expressions of spirituality. ${ }^{10} 1213$ The model is referred to as biopsychosocio-existential. ${ }^{14}$ There are two primary reasons for using this model. First, a wide variety of existential meaning-making is encountered in mental health work in these countries. Second, access to such information provides important knowledge for interpreting the model's other components.

Sweden has become one of the most secular cultures in the world in the sense that the functions of religious-thinking, behaviour and institutions have changed or that their social significance has been reduced. ${ }^{15}{ }^{16}$ In 2008 , only $17 \%$ of respondents answered 'yes' to the question 'Is religion an important part of your daily life?' constituting the second lowest result among 143 countries. $^{17}$ Thus, devout Christians among ethnic-Swedes can be understood as an overlooked minority group mainly belonging to Christian Lutheran denominations. ${ }^{18}$ Meanwhile, most ethnic-Swedes though technically members of the Church of Sweden view Lutheran Christianity as a part of their cultural heritage-but not as a belief system that influences daily living. ${ }^{19}$ Secularism also characterises the healthcare system, often viewing this type of existential information as unimportant for medical practice. Even in palliative care, where existential concerns are understood as essential components of holistic care, there has been uncertainty about how to deal with them in Sweden. This is connected to a fear of violating patient privacy. ${ }^{20}{ }^{21} \mathrm{In}$ our own work within general practice and psychiatry, we have encountered patients wanting to talk about existential concerns in relation to their suffering, but with the experience of this wish not being recognised. ${ }^{142} 23$

Since this study focuses on a group that is devoutly religious and belonging to the majority secular culture, we will look particularly at the results of studies concerning religious worldviews. Addressing religious issues has since the beginning of the 1990s become an important and growing component in mental health research in western world contexts. ${ }^{24-27}$ This research has been conducted primarily in countries such as the USA where religion is part of the dominant culture. ${ }^{27}$ Religious faith has often, but not exclusively, been identified as having a protective effect, or facilitating coping in relation to, for example, depression, substance abuse, schizophrenia, psychosis and suicide. ${ }^{24-31}$ However, religious faith also, mainly in European contexts, has been identified as a risk factor for mental ill health. ${ }^{32}{ }^{33}$ It can create internal and external conflicts for patients with mental ill health, ${ }^{29}{ }^{34}$ influencing motivation to seek treatment and compliance. ${ }^{35}$ Religious beliefs and practices are considered important to public mental health promotion. ${ }^{36} 37$

Very little research has been conducted in Sweden and Scandinavia regarding religious or other worldviews and mental health. ${ }^{10} 12{ }^{13}$ Most studies are related to immigrant groups with different ethnicities. The few studies concerning ethnic-Swedes described a wide variety of worldviews, including religious, as possible resources in relation to mental ill health, ${ }^{38} 39$ as well as that Swedish patients wanted to talk about their worldviews in their contacts with healthcare. ${ }^{39-42}$

Mental ill health is increasing in Sweden. ${ }^{43} 44$ Of patients in primary care, 20-30\% suffer from symptoms of psychological distress and anxiety, and depressive emotions are common in the population. ${ }^{45} 46$

In light of these challenges, we conducted a study of devout Christians from the ethnic-Swedish majority population, having suffered from mental ill health: their experiences of illness, treatment and interaction with the healthcare system. The term devout here means that their cultural and existential meaning-making has informed their decision-making processes and their interpretations of illness and health. ${ }^{47} 48$ The choice of this minority group from the ethnic-majority culture was made due to their marginalised status in the culture and absence in mental health research. The overall purposes for the research were as follows:

1. To create a deeper understanding, in a Swedish secular healthcare context, of meaning-making in an ethnic Swedish group of Christian patients with mental ill health, not earlier investigated;

2. To acquire further knowledge regarding the importance of access to patients' systems of meaning-making in relation to mental ill-health concerns.

In this article, we present the first part of a larger study. The research question in this substudy was: 
Table 1 Information about the participants

\begin{tabular}{|c|c|}
\hline Age (years) & $\begin{array}{r}30-73 \text { (range) } \\
50 \text { (mean) }\end{array}$ \\
\hline \multicolumn{2}{|l|}{ Gender } \\
\hline Female & 12 \\
\hline Male & 5 \\
\hline \multicolumn{2}{|l|}{ Professional sector } \\
\hline Health and social care (nurse, medical student, social worker, personal assistant) & 4 \\
\hline Education (preschool teacher, secondary school teacher, art teacher, camp director) & 4 \\
\hline Technical/industrial (industrial worker, civil engineer) & 3 \\
\hline Service (post office cashier, shop assistant) & 2 \\
\hline Religious organisation/denomination (priest, pastor, parish educator) & 3 \\
\hline Did not identify work sector & 1 \\
\hline \multicolumn{2}{|l|}{ Work-related status } \\
\hline Able to work & 10 \\
\hline Unable to work due to mental ill health & 6 \\
\hline Did not provide information on work-related status & 1 \\
\hline \multicolumn{2}{|l|}{ Religious affiliation (some belonging to more than one) } \\
\hline Church of Sweden* & 3 \\
\hline Catholic church & 2 \\
\hline Evangelical Free Church & 5 \\
\hline Faith movement & 3 \\
\hline Orthodox church & 1 \\
\hline Pentecostal church & 6 \\
\hline Swedish Evangelical Mission† & 2 \\
\hline \multicolumn{2}{|l|}{ Diagnosis (self-reported, can be multiple for each participant) } \\
\hline Bipolar disorder & 2 \\
\hline Depression & 9 \\
\hline Drug abuse & 1 \\
\hline Adjustment disorder & 2 \\
\hline Panic disorder & 2 \\
\hline GAD & 2 \\
\hline ADHD (attention deficit hyperactivity disorder) & 2 \\
\hline Psychosis & 3 \\
\hline PTSD & 4 \\
\hline Schizophrenia & 1 \\
\hline Personality disorder & 2 \\
\hline
\end{tabular}

What meaning did their Christian faith have for the participants' experience and understanding of mental ill health?

\section{METHOD}

\section{Setting}

To answer the overall study's questions, we chose a qualitative method, based on in-depth interviews with persons with an ethnic Swedish background. Criteria for participation were that they defined themselves as devout Christians, were actively involved in a congregation and had experienced mental ill health of any kind to the degree that such led to contact with the healthcare system.

\section{Recruitment and sampling}

Participants were recruited mainly with the help of leaders of congregations in different parts of Sweden. The leaders had, through their work, contact with people that matched the study criteria and were invited to ask some if they were interested in receiving information about the study. The leaders were not informed whether they later chose to participate. For those interested, an information letter was posted and a telephone call was made 2 weeks later. Two men and one woman then declined participation. Two were recruited through another participant, the so-called snowball method, ${ }^{49}$ and two were recruited through acquaintances. The participants were informed that they at any time, and without providing a reason, could choose to leave the study.

A purposeful sampling strategy was used to obtain a wide range of experiences. Denominational affiliation was considered essential, as denominations have different theological profiles and represent different Christian traditions and rituals. More women than men are active congregation members, and more women are diagnosed with mental ill-health concerns, which is why a balance 
reflecting these aspects was sought. Homosexual, bisexual, transgender and queer (HBTQ) persons have mental ill-health problems to a greater degree than heterosexuals and are not always accepted in Christian denominations. We wanted to try to reflect something of their experiences. Participants in the study are briefly presented in table 1 .

\section{Data collection and analysis}

We, the researchers, are general practitioners (AF, Ale, ALi) and a psychologist (VDM) with many years of experience in meeting patients with mental ill health. One of us (ALi) conducted all the interviews. The participants declared that they preferred to speak to a person well acquainted with their belief system. This also proved important to understand fully their vocabulary. The interview topic areas were: (1) experiences of being afflicted by mental ill health, (2) thoughts about what can bring relief and cure, (3) experiences with receiving healthcare and (4) the importance of faith for all of this. The interview topic areas encompass all areas in the larger study; focus here is given primarily to the first topic, together with the fourth.

All interviews covered the four topic areas. In order for each participant to approach the topics in her or his own way, the interviews took the form of conversations, in which the informants' own thoughts, experiences and associations were given priority. Two participants were interviewed twice, the others once. The interviews lasted 60-120 min, were audio-recorded and printed verbatim. They were analysed through systematic text condensation (STC), a method inspired by Giorgi's phenomenological analysis method. ${ }^{50}$ The procedure included four main steps: (1) reading and re-reading all interviews to get a total impression and create themes related to the research question, (2) identifying and sorting meaning units relevant to the themes (coding), (3) capturing the meaning of codes and subcodes through creating artificial quotes in first person and (4) creating analytical descriptions and concepts. This work involved several reading and discussion rounds among all the researchers before reaching the final results, which reflect a high level of inter-researcher agreement in the coding, selection and analytical description processes.

A preliminary coding was performed parallel to conducting new interviews. The material gradually became large and comprehensive, and the last interviews gave rich illustrations but without leading to the creation of new themes. It was also important to avoid an unwieldy amount of material. ${ }^{51}$ We therefore sought no additional informants after having interviewed 17 people.

\section{RESULTS}

These are reported under three main categories: 'Relationship with God', 'Symptoms and existential meaning-making' and 'Explanations of illness', with subthemes as follows in text and tables. A working hypothesis that experiences would differ based on denominational affiliation was not supported by the material and is not accounted for here.

God was by most participants referred to as 'he', with only one exception when a gender-neutral term was used.

\section{Relationship with God}

Importance of the relationship

All participants described their faith as a deep personal relationship with God, often considered the most important relationship in their lives, and, consequently, of central importance during their time(s) of illness.

Many had felt that 'God was still there' despite severe anxiety and depression, and this had protected them against the overwhelming loneliness that illness otherwise implied. The conversations with God, prayer, constituting the basis of the relationship, could continue and often intensified. God's presence gave comfort, the possibility 'to just collapse in his arms', and sometimes relief during a psychosis. The relationship became a 'lifeline' that permitted human dignity and self-image to be preserved intact. For others, the experience was the total opposite; God turned away from them. They felt abandoned.

\section{Asymmetries in the relationship}

Their relationship with God was unequal. Many described God as a father and helper, strong and with many resources. The feeling that 'for God all things are possible' could give hope of recovery. Unexplained help, for instance when money turned up in times of economic distress, was seen as a sign of God's care. At other times, the help could be through an internal strength to endure and evolve as a person. Gratitude for such help was great. Conversely, disappointment, and sometimes anger, was great when God did not answer their prayers for help. Some felt 'betrayed' when afflicted by mental ill health, a difficulty in which they could find no meaning.

Some participants believed that God had a specific plan for their lives; they had received a 'calling' to be of use in a particular way. This could be understood as a promise from God, giving hope through the idea that 'God believes in me when no one else does'. For others, the calling instead implied expectations that they could not meet. Some experienced God as a judge. If they had failed in living by the moral standards that they perceived God represented, for example, concerning alcohol or sexuality, the shame of their failures created a distance in the relationship or a need to 'hide from God'. Disappointing God's calling, or seeing God as a judge, aroused fears of God's response to them after death, when they stood before God's court.

\section{Movements in the relationship}

The relationship with God was dynamic and changing over time, which was of great importance, sometimes 
Box 1 Quotations for 'Relationship with God'

\section{Importance of the relationship}

"He is there! He is always there. He is my best friend. I can always talk to Him. [...] He always does come. Amidst all this sorrow and pain, He can despite all, still come, with His peace. You can, despite all, feel calmness." (P6)

"I was so alone in my experience, and finally came to the point asking: Am I all alone, or is God with me? In that period there was a deep loneliness!" (P5)

Asymmetries in the relationship

"There is still a kind of hope, a greater power than myself, who can sort out the things that you cannot fix yourself." (P3)

"When my life is over, I will ask, what did I actually do with my life? Then I have this feeling that God will say; "Well, what did you do with your treasure? What happened to what I gave you? You hid it." (P13)

\section{Movements in the relationship}

"It was like I had myself to blame, that I was on the wrong track, and God was that stern parent that would discipline me. I was to be disciplined. There was always an element of dissatisfaction, I never was fully sufficient. [...] That my view of God changed so much for the better made it possible for me to feel so much more at home in real life, so to speak." (P10)

"I was angry at God, too, of course. Why are things the way they are? Why are our children sick?... Then you fight with Him. And that is also healing." (P2)

crucially so for recovery. The view of God could change, from the stern and judgmental to the patient, merciful and full of grace. When such happened, burdening demands were lessened; anxiety and psychotic symptoms abated and suicidal thoughts were kept at a distance. For those who felt betrayed by God, the possibility of showing strong negative feelings in God's presence was perceived as part of a healing process. For representative quotations, see box 1 .

\section{Symptoms and existential meaning}

\section{Usual symptoms and their existential meaning}

Participants described well-known symptoms of mental ill health that struck them. For many, the symptoms also had an existential meaning. Feelings of guilt and shame made them doubt their right to be God's child. Perhaps God's infinite mercy was finite for them. Existential interpretations framing psychotic delusions could be very frightening; they thought that they prevented God's presence and were unworthy to be in God's or other Christians' vicinity. In isolated cases, psychotic experiences were interpreted as a support from God that relieved anxiety.

Thoughts of suicide had plagued several. Some had spoken with God about their death wish and asked God to intervene and 'take them home'. Others thought that God should have been merciful and received them into his arms if they chose that escape. Two participants had experienced God's intervention when they were about to commit suicide. They saw this as a sign of God's care

\section{Box 2 Quotations for 'Symptoms and existential meaning'}

\section{Usual symptoms and their existential meaning}

In the end, it became a voice. It said that I could not show myself, and could not be seen, and could not go to church because I am...not really pure...I would ruin things for other Christians if I were near them. (P13)

"No, no. No. No, because that is wrong. I do not want to kill myself because. ...I do not think God wants man to do that. [...] ... but even if you are heading for the kingdom of the dead God is also there." (P17)

"Also this, yes the feeling of not wanting to live anymore was very strong. (crying) ....and it is still there now and then, and that I feel this, this is also very shameful... To not, to not experience joy in life, that is actually shameful. Especially if one is God's child..." (P16)

\section{Experiencing existential consequences}

"I put the Bible in a drawer, because I couldn't bear, I felt so badly that I could not bear to read it." (P17)

"Besides that in one way being barred from participating so much, it is also... there are no songs of praise inside me in some way. It seems hypocritical to stand there singing: "God how happy I am." (P2)

"I still fight, somewhat, with this, with the silence. This NOTHING all those years."

Interviewer: "The Silence?" "Yes, from God to me, and, back to God in some way." (P14)

and assurance that their life remained worthy to be lived. For others who had strong internal standards that a child of God should feel gratitude and joy in life, the discrepancy between norm and feelings became too large, and their shame intensified. This ultimately also could be protective towards suicide; they were not able to make God even more disappointed.

\section{Existential consequences}

In addition to their symptoms, the informants described how their faith life was affected negatively by the illness. This concerned important things in their everyday life as devout Christians.

Many were not able to attend church services, they were too tired, felt they no longer fit in or were ashamed of their illness. The consequences represented more than only a lack of social interaction; the loss of a way to express their faith and spend time with God. Someone described it as 'losing her spiritual home'. Fatigue and apathy could interfere with reading the Bible and spiritual exercises, which strengthened the feelings of loneliness and failure. Not having the energy or ability to pray, to express themselves in words, was particularly difficult. For some, prewritten prayers or knowing that friends in the congregation prayed for them became a replacement. For others, the inability to pray brought a strong fear that their most important relationship was broken. For representative quotations, see box 2. 


\section{Explanations of illness}

\section{Biopsychosocial explanations}

As explanations for their illness, informants reported a general acceptance of biopsychosocial explanatory models found in Western medicine. Explanations cited included abuse in childhood or adulthood, heredity, somatic illness, life crises in adulthood and extreme stress at work or in connection with a child's illness. Some named bullying because of their Christian faith or in the congregation because of a bisexual orientation, as (partial) causes. The view that people can suffer from mental ill health without any directly identifiable cause also was voiced.

\section{Existential explanations}

There also emerged explanations based on the participants' Christian faith. These concerned the relationship with God; that they had not trusted unreservedly to surrender themselves into his hands, that they had been disappointed in him or that they had had a frightening view of God with too strong internal demands to "work for him'. This included thoughts about lacking 'sanctification'; that they had not sufficiently devoted themselves to specific spiritual exercises that shape character. There were also thoughts that suffering is a part of the Christian life.

Several participants described explicitly existential explanations, based on the perspective of a good and evil existential world; demons could attack or 'possess' a person. An attack implied a serious but manageable problem, and integrity could be preserved. Those who believed that demons took over the person inside described huge fear.

\section{Duplicate explanation-consonance and dissonance}

Most participants included a biopsychosocial and an existential explanation, but the fit and the valence varied. Three distinct patterns were identified. They were dynamic; the same individual could at various times and circumstances show evidence of different patterns operating.

(a) Comprehensive thinking and consensus

In this pattern, existential and biopsychosocial explanations were integrated. The human being was seen as a whole, composed of spirit, soul and body; if one part was affected, so was the whole person. This approach led to cognitive consonance; an internal correspondence between meaning systems that were experienced as consistent and therefore stable.

(b) Division and parallel functions

Existential and biopsychosocial explanations existed parallel to each other. One's own mental illness could be explained by biopsychosocial factors or existential. Of fundamental importance was an existential purpose for the illness; God used the experience to form the person towards greater maturity. This brought meaning and security and led to cognitive consonance because
Box 3 Quotations for 'Explanations of illness'

\section{Biopsychosocial explanations}

"The thing was that I was a victim of abuse. My father could not set limits. So he abused me. Because I was so affectionate and he could not control himself. And then my brother as well." (P8) "I have mental illness in my family. That is there. So I have, I have a psychological vulnerability if I say so." (P10)

\section{Existential explanations}

"In my experience when one has started using drugs and becomes an addict one absolutely becomes influenced by a demonic force that does not want one to stop taking drugs. That wants one to totally lose faith and commit suicide as a way out in the end." (P11)

"This darkness that I have inside. And it is truly like, it feels like the Devil himself has come, baaarrrcgh! (Makes a face and spreads out her hands in front of her.) And I just swear, I just curse, it just rushes out of me, black. Black, black, black." (P8) Double explanations - consonance and dissonance

(a) "And for me this is nothing problematic, as I see it this way. It [the illness] is both spiritual and of course psychological also." (P5)

(b) "It is no punishment, and I do not believe that, that God wants us to have illnesses, absolutely not. Instead $\mathrm{He}$, He lets it happen. He lets it happen and, and has a, something good comes from it. You know, He has a plan with allowing things to happen, so to speak." (P10)

(c) "But if one is doubtful about... I sometimes thought that it is almost, you know, a question of which leg to stand on? How...can one believe that Freud was right? ...The entire worldview. If one has to...I think that sometimes maybe one believes that just to receive help from psychiatry one needs to buy the worldview that it is built upon." (P1)

everything, regardless of explanatory model, was understood as a part of God's plan.

(c) Division and competitive functions

This approach meant a clearer division and competition between these two explanatory models, and it was important for individuals to understand where their own symptoms belonged; were they due to shortcomings in the person's spiritual exercises or to 'hormonal imbalances in the brain'? The result was cognitive dissonance, where two meaning systems clashed and inner loyalty conflict arose. If the person accepted the biopsychosocial explanatory model, there was a sense of having betrayed the principles of faith. If the person instead used the existential explanatory model, feelings arose of not being able to rely on their intellect, their schooling or healthcare. For representative quotations, see box 3 .

\section{DISCUSSION}

\section{Summary of main findings and comparison with existing}

\section{literature}

Our study of individuals from the religious minority group of devout Christians from the ethnic-Swedish secular majority population shows that their religious worldview was essential to their individual experience 
and understanding of mental health and ill health. Though a seemingly homogenous group, the results also show important individual variations.

In relation to the public mental health ROAMER research agenda frame, ${ }^{3}$ the findings make several contributions. First, they expand the area of culture through exploration of a religious minority group of the dominant culture in a primarily secular context. They point to the need for planned strategies that focus on individual, group and societal aspects for public mental health promotion. ${ }^{52}$ Second, the findings identify specific experiences of existential meaning that appear to support well-being and might function as protective factors. This does not obscure or negate other experiences of existential meaning that might be analysed as risk factors. Different experiences of existential meaning, even for the same individual, might contribute to protection and risk. ${ }^{10-37}$ Third, findings point to the need for the inclusion of existential meaning information into a holistic and integrated clinical model for understanding patients' perceptions and explanations. The perception of a living relationship with God, often seen as the most important of relationships for the participants, needs to be included in the social as well as the existential components of the model.

For the participants, the interactions of biopsychosocial and existential explanatory systems of illness causation were varied and not infrequently involved painful struggles with what weight to give them. The three different patterns of interaction identified: (a) comprehensive thinking and consensus; (b) division and parallel functions; and (c) division and competitive functions, contribute a working clinical typology. Participants holding worldviews where existential explanations competed with medical explanations often experienced very difficult situations, making it also difficult to build a trusting therapeutic alliance. Here, understanding of their cultural context might have located additional resources for use in the treatment process. ${ }^{24} 5354$ The participants' view of God, as well as their explanatory models, were dynamic over time, which was perceived as important for recovery. In line with earlier findings, these perceptions were unique to the individual and did not depend on denominational affiliation. ${ }^{55}$

The typology identified here can assist mental health professionals to work person-centered, influencing how patient narratives are heard and used. The typology supports the need for inclusion of cultural and existential information as emphasised in the DSM-5, and especially the field study findings of the clinical instrument, the Cultural Formulation Interview (CFI) ${ }^{56}$ showing relevance for diagnostic and treatment processes.

\section{New findings}

The study shows that each individual's way of making existential meaning is vital to his/her experiences and explanations of mental health and ill health. The finding of the significance and diverse meanings of a relationship with God brings a new category of relationships for exploration in relation to mental ill health. The study contributes a new typology for assessing how a patient's existential meaning informs his or her understandings of the illness experience. The study shows the need for a more integrated model, including an existential dimension, for culturally informed research and clinical practice.

\section{Strength and limitations of the study}

Most research in the area of existential information and mental health is quantitative. As this study concerns an understudied minority group, we consider a qualitative approach important in order to reflect the complexity of the topic ${ }^{20}$ and to create conceptual knowledge to generate hypotheses for further exploration in larger, quantitative, studies.

In Western European contexts, research on cultural aspects of health has often focused on ethnic minorities. We wanted to pay attention to a rather 'invisible' subgroup of the ethnic-majority population whose needs in healthcare risk being ignored.

Of the 17 participants, 14 belonged to Lutheran Christian denominations, the branch of Christianity that largely dominates in Sweden. Owing to our sample, transferability of findings by nature is limited.

We consider it a strength that the interviewer was fully accepted as 'one of us' by the participants. This yielded rich and trustworthy information that would have been difficult to gain otherwise. The continuous discussion among all of the researchers was essential for clarifying concepts and for a deeper majority cultural understanding of this minority religious cultural framework.

\section{Implications for policymakers and clinical practice}

WHO recommends a person-centered approach in healthcare, ${ }^{4}$ but existential questions have long been regarded as unimportant or even offensive, and therefore avoided, in secular healthcare contexts. Our study, in line with other research, shows that important information regarding mental ill health and resources for recovery is lost, if person-centered care does not include patients' central systems of meaning-making. The results support the need, in clinical practice, for accessing cultural and existential information for all patients.

It is not possible, nor necessary, for healthcare workers to know about all the various types of existential meaning-making that exist in our increasingly multicultural societies. Instead, the challenge is to develop routines for obtaining existential information about the individual patient and for assessing how this might influence his/her health.

In light of this, and for the purpose of public mental health promotion, we consider it important for the healthcare system, not least within psychiatry and primary care, to integrate the biopsychosocio-existential dimensions into culturally informed clinical models for a more thorough understanding of a patient's concerns, 
symptoms and resources and for planning treatment strategies for addressing mental ill health.

Further research is needed regarding the experiences and needs of patients in relation to existential meaningmaking in healthcare encounters. We also suggest investigating how the CFI could be adapted and used in psychiatric and primary care settings.

\section{Author affiliations}

${ }^{1}$ Department of Public Health and Clinical Medicine, Division of Family Medicine, Umeå University, Umeå, Sweden

${ }^{2}$ Department of Theology, Psychology of Religion and Cultural Psychology, Uppsala University, Uppsala, Sweden

${ }^{3}$ Mental Health Division, Innlandet Hospital Trust, Hamar, Norway

${ }^{4}$ Department of Clinical Sciences, Umeå University, Umeå, Sweden

Acknowledgements The authors are most grateful to the participants for sharing their experiences with them.

Contributors ALi conceived of the study and designed it together with AF. ALi, ALe and AF performed the initial analysis, with VDM contributing substantially to the final analysis and interpretation. ALi drafted the initial manuscript, finishing it together with AF and VDM. ALe critically read the manuscript several times. AF supervised the project continually. All authors read and approved the final manuscript.

Funding The research was supported by the County Council of Norrbotten, NLL-378851

\section{Competing interests None declared.}

Ethics approval Written informed consent was obtained from the participants. The study was approved by the Regional Ethical Committee of Umeå, Sweden. Reference no. 2012-258-310̈.

Provenance and peer review Not commissioned; externally peer reviewed.

Data sharing statement No additional data are available.

Open Access This is an Open Access article distributed in accordance with the Creative Commons Attribution Non Commercial (CC BY-NC 4.0) license which permits others to distribute, remix, adapt, build upon this work noncommercially, and license their derivative works on different terms, provided the original work is properly cited and the use is non-commercial. See: http:// creativecommons.org/licenses/by-nc/4.0/

\section{REFERENCES}

1. Murray CJL, Vos T, Lozano R, et al. Disability-adjusted life years (DALYs) for 291 diseases and injuries in 21 regions, 1990-2010: a systematic analysis for the Global Burden of Disease Study 2010. Lancet 2012;380:2197-223.

2. Wittchen HU, Jacobi F, Rehm J, et al. The size and burden of mental disorders and other disorders of the brain in Europe 2010. Eur Neuropsychopharmacol 2011;21:655-79.

3. Forsman AK, Wahlbeck K, Aarøe LE, et al., ROAMER Consortium Research priorities for public mental health in Europe: recommendations of the ROAMER project. Eur J Publ Health 2015;25:249-54

4. Mezzich JE, Salloum IM. Clinical complexity and person-centered integrative diagnosis. World Psychiatry 2008;7:1-2.

5. Lewis-Fernández R, Aggarwal NK, Bäärnhielm S, et al. Culture and psychiatric evaluation: operationalizing cultural formulation for DSM-5. Psychiatry 2014;77:130-54.

6. Engel GL. The clinical application of the biopsychosocial model. $A m$ J Psychiatry 1980;137:535-44.

7. Josephson AM, Peteet JR. Handbook of spirituality and worldview in clinical practice. Arlington (VA): American Psychiatric Publishing, 2004.

8. Kirkengen AL, Ekeland TJ, Getz L, et al. Medicine's perception of reality - a split picture: critical reflections on apparent anomalies within the biomedical theory of science. J Eval Clin Pract 2016;22:496-501.
9. McEwen BS, Getz L. Lifetime experiences, the brain and personalized medicine: an integrative perspective. Metabolism 2013;62(Suppl 1):S20-6.

10. DeMarinis V, Ulland D, Karlsen KE. Philosophy's role for guiding theory and practice in clinical contexts grounded in a cultural psychiatry focus: a case study illustration from southern Norway. World Cultur Psychiatry Res Rev 2011;6:47-56.

11. DeMarinis V, Scheffel-Birath $\mathrm{C}$, Hansagi $\mathrm{H}$. Cultural analysis as a perspective for gender-informed alcohol treatment research in a Swedish context. Alcohol Alcohol 2009;44:615-9.

12. la Cour P. Existential and religious issues when admitted to hospital in a secular society: patterns of change. Ment Health Relig Cult 2008;11:769-82.

13. la Cour P, Hvidt NC. Research on meaning-making and health in secular society: Secular, spiritual and religious existential orientations. Soc Sci Med 2010;71:1292-9.

14. Haug SH, Danbolt LJ, Kvigne K, et al. How older people with incurable cancer experience daily living: a qualitative study in Norway. Palliat Support Care 2015;13:1037-48.

15. DeMarinis $\mathrm{V}$. The impact of postmodernization on existential health in Sweden: Psychology of religion's function in existential public health analysis. Arch Psychol Relig 2008;30:57-74.

16. Inglehart R, Baker WE. Modernization, cultural change, and the persistence of traditional values. Am Sociol Rev 2000;65:19-51.

17. Crabtree Steve PB. What Alabamians and Iranians have in common 2009. http://www.gallup.com/poll/114211/

Alabamians-Iranians-Common.aspx (accessed 20 Jan 2016).

18. ST-Nämnden för statligt stöd till trossamfund. (National Swedish Organization for support of religious denominations), 2012. http:// www.sst.a.se/inenglish.4.7f968fc211 eeec933de800011945.html (accessed 20 Jan 2016).

19. af Burén A. Living Simultaneity. On religion among semi-secular Swedes [dissertation]. Stockholm: Södertörn University, 2015.

20. DeMarinis V. Tvärrkulturell vård i livets slutskede. Att möta äldre personer med invandrarbakgrund (Cross-cultural healthcare at the end of life. Meeting older persons with immigrant backgrounds). Stockholm: Studentlitteratur, 1998.

21. Ekedahl M, Wengström $Y$. Nurses in cancer care-stress when encountering existential issues. Eur J Oncol Nurs 2007;11:228-37.

22. Lehti A, Hammarström A, Mattsson B. Recognition of depression in people of different cultures: a qualitative study. BMC Fam Pract 2009;10:53

23. DeMarinis V. Public mental health promotion, meaning-making and existential meaning: challenges for person-centered care of refugees in a secular, pluralistic context. In: Overland G, Guribye E, Lie B, eds. Nordic work with traumatised refugees: do we really care. Newcastle upon Tyne: Cambridge Scholars, 2014:316-24.

24. Gomi S, Starnino VR, Canda ER. Spiritual assessment in menta health recovery. Community Ment Health J 2014;50:447-53.

25. Smith TB, McCullough ME, Poll J. Religiousness and depression: evidence for a main effect and the moderating influence of stressful life events. Psychol Bull 2003;129:614-36.

26. Koenig HG. Research on religion, spirituality, and mental health: a review. Can J Psychiatr 2009;54:283-91.

27. Southwick SM, Vythilingam M, Charney DS. The psychobiology of depression and resilience to stress: implications for prevention and treatment. Annu Rev Clin Psychol 2005;1:255-91.

28. Bernards S, Graham K, Kuendig H, et al. 'I have no interest in drinking': a cross-national comparison of reasons why men and women abstain from alcohol use. Addiction 2009;104:1658-68.

29. Grover S, Davuluri T, Chakrabarti S. Religion, spirituality, and schizophrenia: a review. Indian J Psychol Med 2014;36:119-24.

30. Dein S, Bhui KS. At the crossroads of anthropology and epidemiology: current research in cultural psychiatry in the UK. Transcult Psychiatry 2013:50:769-91.

31. Wu A, Wang JY, Jia CX. Religion and completed suicide: a meta-analysis. PLoS One 2015;10:1-14.

32. Leurent B, Nazareth I, Bellón-Saameño J, et al. Spiritual and religious beliefs as risk factors for the onset of major depression: an international cohort study. Psychol Med 2013;43:2109-20.

33. King M, Marston L, McManus S, et al. Religion, spirituality and mental health: results from a national study of English households. Br J Psychiatry 2013;202:68-73.

34. Abu-Raiya $\mathrm{H}$, Pargament $\mathrm{KI}$, Krause $\mathrm{N}$. Religion as problem, religion as solution: religious buffers of the links between religious/spiritual struggles and well-being/mental health. Qual Life Res 2016;25:1265-74.

35. Touchet B, Youman K, Pierce A, et al. The impact of spirituality on psychiatric treatment adherence. J Spiritual Ment Health 2012;14:259-67. 
36. Rutz W. A need to rethink social psychiatry in Europe. Lancet 2004;363:1652.

37. Campion J, Bhui K, Bhugra D. European Psychiatric Association (EPA) guidance on prevention of mental disorders. Eur Psychiatry 2012;27:68-80.

38. Hultsjö S, Blomqvist KB. Health behaviors as conceptualized by individuals diagnosed with a psychotic disorder. Issues Ment Health Nurs 2013;34:665-72.

39. Erdner A, Andersson L, Magnusson A, et al. Varying views of life among people with long-term mental illness. J Psychiatr Ment Health Nurs 2009;16:54-60.

40. Strang S, Strang P, Ternestedt BM. Existential support in brain tumor patients and their spouses. Support Care Cancer 2001;9:625-33.

41. Westman B, Bergenmar M, Andersson L. Life, illness and deathexistential reflections of a Swedish sample of patients who have undergone curative treatment for breast or prostatic cancer. Eur J Oncol Nurs 2006;10:169-76.

42. Koslander T, Arvidsson B. Patients' conceptions of how the spiritual dimension is addressed in mental health care: a qualitative study. $J$ Adv Nurs 2007:57:597-604.

43. Johansson SE, Midlöv $P$, Sundquist $J$, et al. Longitudinal trends in good self-rated health: effects of age and birth cohort in a 25-year follow-up study in Sweden. Int J Public Health 2015;60:363-73.

44. The Public Health Agency of Sweden. Folkhälsan i Sverige. Årsrapport 2014 (Public Health in Sweden, Annual Report 2014). 2014. http://www.folkhalsomyndigheten.se/publicerat-material/ publikationer/Folkhalsan-i-Sverige-arsrapport-2014/ (accessed 20 Jan 2016).

45. Kallioinen M, Bernardsson J, Grohp M, et al. Mental illness a problem among primary health care patients. A questionnaire comprising more than 2000 patients. Lakartidningen 2010;107:1545-7.

46. Waller $\mathrm{G}$, Janlert $\mathrm{U}$, Hamberg $\mathrm{K}$, et al. What does age-comparative self-rated health measure? A cross-sectional study from the Northern Sweden MONICA Project. Scand J Publ Health 2016;44:233-9.

47. Helman CG. Culture, health and illness. London: Hodder Education, 2007.

48. Kleinman A, Benson P. Anthropology in the clinic: the problem of cultural competency and how to fix it. PLoS Med 2006;3:e294.

49. Patton MQ. Qualitative evaluation and research methods. Newbury Park (CA): Sage, 1990:182-3.

50. Malterud K. Systematic text condensation: a strategy for qualitative analysis. Scand J Public Health 2012;40:795-805.

51. Kvale S. An introduction to qualitative research interviewing. Thousand Oaks (CA): Sage, 1996:101.

52. Kalra G, Christodoulou G, Jenkins R, et al., European Psychiatry Association. Mental health promotion: guidance and strategies. Eur Psychiatry 2012;27:81-6.

53. Moreira-Almeida A, Koenig HG, Lucchetti G. Clinical implications of spirituality to mental health: review of evidence and practical guidelines. Rev Bras Psiquiatr 2014;36:176-82.

54. Pulchaski C. Spiritual assessment in clinical practice. Psychiatry Annals 2006;36:150-5.

55. Huguelet $\mathrm{P}, \mathrm{Mohr} \mathrm{S}$, Gilliéron $\mathrm{C}$, et al. Religious explanatory models in patients with psychosis: a three-year follow-up study. Psychopathology 2010;43:230-9.

56. Gellerman D, Hinton D, Lu FG. Supplementary model 5: spirituality, religion and moral traditions. In: Lewis-Fernández R, Krishan Aggarwal $\mathrm{N}$, Hinton L, et al., eds. DSM-5 handbook on the cultural formulation interview. Washington (DC): American Psychiatric Publishing, 2016:118-122. 